University of Nebraska - Lincoln

DigitalCommons@University of Nebraska - Lincoln

$5-15-2003$

\title{
CoPt hard magnetic nanoparticle films synthesized by high temperature chemical reduction
}

\author{
Yucheng Sui \\ University of Nebraska-Lincoln, ysui2@unl.edu \\ Lanping Yue \\ University of Nebraska-Lincoln, lyue2@unl.edu \\ Ralph Skomski \\ University of Nebraska-Lincoln, rskomski2@unl.edu \\ Xingzhong Li \\ University of Nebraska-Lincoln, xli2@unl.edu \\ J. Zhou \\ University of Nebraska - Lincoln \\ See next page for additional authors
}

Follow this and additional works at: https://digitalcommons.unl.edu/physicssellmyer

Part of the Physics Commons

Sui, Yucheng; Yue, Lanping; Skomski, Ralph; Li, Xingzhong; Zhou, J.; and Sellmyer, David J., "CoPt hard magnetic nanoparticle films synthesized by high temperature chemical reduction" (2003). David Sellmyer Publications. 35.

https://digitalcommons.unl.edu/physicssellmyer/35

This Article is brought to you for free and open access by the Research Papers in Physics and Astronomy at DigitalCommons@University of Nebraska - Lincoln. It has been accepted for inclusion in David Sellmyer Publications by an authorized administrator of DigitalCommons@University of Nebraska - Lincoln. 


\section{Authors}

Yucheng Sui, Lanping Yue, Ralph Skomski, Xingzhong Li, J. Zhou, and David J. Sellmyer 


\title{
CoPt hard magnetic nanoparticle films synthesized by high temperature chemical reduction
}

\author{
Y. Sui, ${ }^{\text {a) }}$ L. Yue, R. Skomski, X. Z. Li, J. Zhou, and D. J. Sellmyer \\ Department of Physics and Astronomy and Center for Materials Research and Analysis, \\ University of Nebraska, Lincoln, Nebraska 68588-0111
}

(Presented on 14 November 2002)

\begin{abstract}
The synthesis of hard-magnetic CoPt nanoparticle films by hydrogen reduction of Co nitride and $\mathrm{Pt}$ chloride mixture is reported. Thin porous alumina films are adopted as the carrier of the initial aqueous solution and of the final reducing products of CoPt nanoparticles. It is found that chemical ordering of $L 1_{0}-\mathrm{CoPt}$ occurs above $400^{\circ} \mathrm{C}$. Partial phase transformation occurs in the alumina substrate when the treatment temperature is higher than $600^{\circ} \mathrm{C}$. The film coercivity increases with increasing annealing temperature and reaches a maximum value of $24.2 \mathrm{kOe}$ when the reduction is carried out at $700^{\circ} \mathrm{C}$ for $2 \mathrm{~h}$. (C) 2003 American Institute of Physics. [DOI: 10.1063/1.1544501]
\end{abstract}

\section{INTRODUCTION}

The high magnetic anisotropy of FePt and CoPt with ordered $L 1_{0}$ structure, $K_{1}=6.6$ and $4.9 \mathrm{MJ} \mathrm{m}^{-3}$, respectively, makes nanoparticulate films of these compounds promising candidates for high-density magnetic recording media and high-energy-product nanocomposite permanent magnets. ${ }^{1-4}$ Recently, Sun et al. have prepared FePt nanoparticles by simultaneous reduction of platinum acetylacetonate and thermal decomposition of iron pentacarbonyl. ${ }^{1}$ Upon annealing at $550^{\circ} \mathrm{C}$, the nanoparticles with facecentered-cubic structure transformed to face-centeredtetragonal particles whose coercivity depends on the annealing temperature. The highest coercivity value was about 20 kOe, which was obtained by annealing at $600{ }^{\circ} \mathrm{C}$ for $1 \mathrm{~h}$. Strongly exchange-coupled FePt nanoparticle assemblies also were obtained. ${ }^{3}$ As an alternative method of material synthesis, we introduce a hydrogen-reduction method for CoPt $L 1_{0}$ nanoparticle film preparation. The magnetic properties of CoPt $L 1_{0}$ nanoparticle films are discussed together with the hydrogen reduction and $\mathrm{CoPt} L 1_{0}$ phase-formation processes.

\section{EXPERIMENTAL METHOD}

Porous alumina films (PAF) were prepared first and used as substrate for the growth of CoPt nanoparticles. Electrochemically polished aluminum plates were anodized in a 0.3 $\mathrm{M}$ oxalic acid aqueous solution at $60 \mathrm{~V}$ for $2 \mathrm{~min}$. Then they were soaked in $5 \%$ phosphorous acid solution for $30 \mathrm{~min}$ for pore widening. The preparation details can be found elsewhere. ${ }^{5}$ By this method, PAFs with a thickness of about $1.8 \mu \mathrm{m}$ and a pore diameter of about $100 \mathrm{~nm}$ were obtained. Second, $1 \mathrm{M}$ aqueous solutions of $\mathrm{Co}\left(\mathrm{NO}_{3}\right)_{2} \cdot 9 \mathrm{H}_{2} \mathrm{O}$, $\mathrm{H}_{2} \mathrm{PtCl}_{6} \cdot 6 \mathrm{H}_{2} \mathrm{O}$, and 1:1 molar ratio of their mixture were

\footnotetext{
a)Electronic mail: ysui@unlserve.unl.edu
}

prepared separately, and were loaded onto the PAFs by spin coating. The loaded films were dried in vacuum for $2 \mathrm{~h}$, then transported into a tubular furnace, and finally treated in flowing hydrogen for specified times and temperatures.

Structural characterization was carried out using x-ray diffractometry (XRD) with $\mathrm{Cu} K \alpha$ radiation. Magnetic properties were measured using a Quantum Design superconducting quantum interference device. Magnetic force microscopy (MFM) images and the topography of the films were obtained using a MFM with low magnetic stray field and highcoercivity MFM tips.

\section{RESULTS AND DISCUSSION}

\section{A. Thermal stability of porous alumina, Co nitride, and Pt chloride}

As all hydrogen reductions were carried out in the PAF, it was important to understand the thermal stability of PAF,

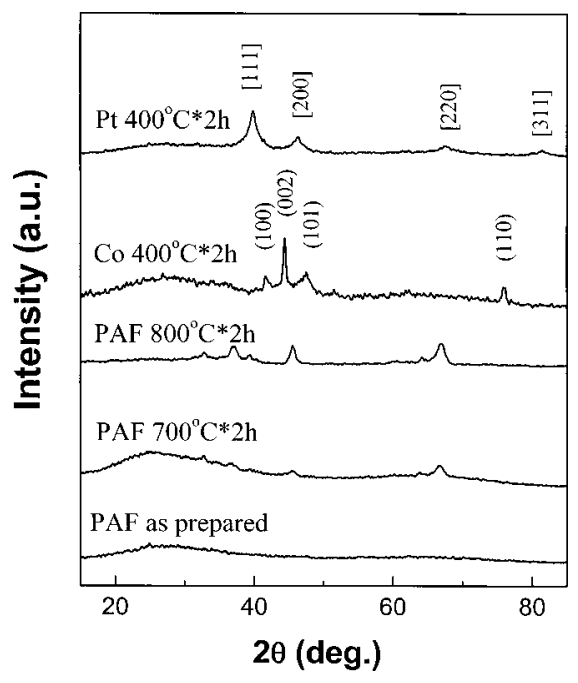

FIG. 1. XRD patterns of as prepared PAF and those treated in hydrogen at 700 and $800^{\circ} \mathrm{C}$, respectively. Pure Co and Pt on PAF by hydrogen reduction at $400{ }^{\circ} \mathrm{C}$ for $2 \mathrm{~h}$. 


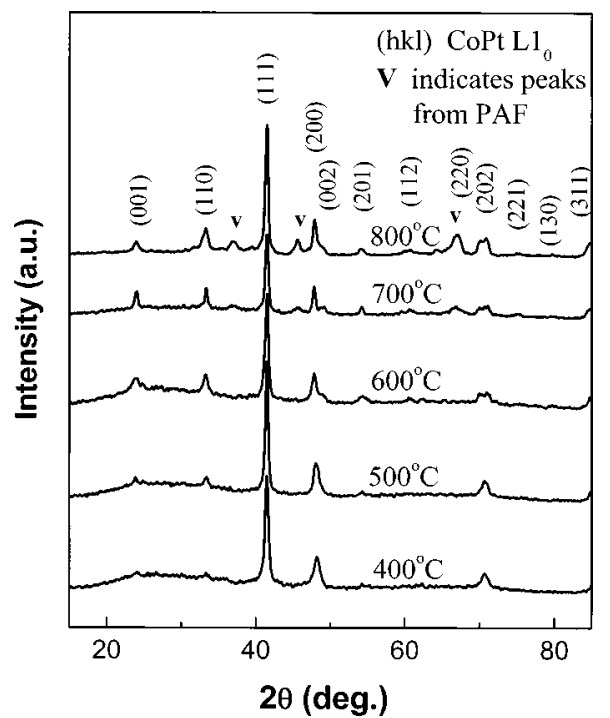

FIG. 2. XRD patterns of CoPt alloys on PAF obtained by hydrogen reduction at different temperature for $2 \mathrm{~h}$. $\mathrm{V}$ indicates the main peaks from alumina matrix due to partial crystalization of PAF.

Co nitride, and Pt chloride salts-particularly with respect to the reducing process, phase formation, etc. XRD patterns of as-prepared PAF and those treated at 700 and $800{ }^{\circ} \mathrm{C}$ for $2 \mathrm{~h}$ in flowing hydrogen are shown in Fig. 1. In order to know the thermal stability of $\mathrm{Co}$ and $\mathrm{Pt}$ salt, two additional samples were made. One PAF was loaded with $1 \mathrm{M}$ aqueous solution of Co nitride, the other one was loaded with Pt chloride solution. Both of them were treated in hydrogen at $400{ }^{\circ} \mathrm{C}$ for $2 \mathrm{~h}$. The corresponding XRD patterns are also shown in Fig. 1.

It is generally recognized that the PAF is amorphous or nanocrystalline with a mean crystallite size of less than $4 \mathrm{~nm} .{ }^{6}$ Our results show that the PAF remained amorphous when the treating temperature is equal to or lower than $600^{\circ} \mathrm{C}$ for $2 \mathrm{~h}$. When the treating temperature is as high as $700^{\circ} \mathrm{C}$, partial crystallization is observed.

Although the treating temperature is only $400^{\circ} \mathrm{C}$, both pure $\mathrm{Pt}$ (fcc) and Co (hexagonal) are produced from their salt, as can be seen from Fig. 1. This means that both Co and Pt salt can be reduced by hydrogen at $400{ }^{\circ} \mathrm{C}$. It also indicates that hydrogen is not only a clean and cheap reducing agent, but also an efficient one. The likely reactions are $\mathrm{Co}\left(\mathrm{NO}_{3}\right)_{2} \cdot 9 \mathrm{H}_{2} \mathrm{O}+\mathrm{H}_{2} \rightarrow \mathrm{Co}+\mathrm{H}_{2} \mathrm{O}+\mathrm{NO}_{2}$ and $\mathrm{H}_{2} \mathrm{PtCl}_{6} \cdot 6 \mathrm{H}_{2} \mathrm{O}+\mathrm{H}_{2} \rightarrow \mathrm{Pt}+\mathrm{H}_{2} \mathrm{O}+\mathrm{HCl}$.

\section{B. Reduction of Co and Pt salt mixture and ordering of $L 1_{0}-\mathrm{CoPt}$}

When the PAFs are loaded with $1 \mathrm{M}$ aqueous solution of $\mathrm{Co}$ and Pt salt mixture, and reduced at specified temperature for $2 \mathrm{~h}$, the CoPt alloy is obtained. The XRD patterns are shown in Fig. 2. When $1 \mathrm{M}$ Co nitride solution alone was reduced on a PAF at $400{ }^{\circ} \mathrm{C}$ for $2 \mathrm{~h}$, the film consists of pure Co nanoparticles with coercivity value of $500 \mathrm{Oe}$. When $1 \mathrm{M}$ Co and Pt salt mixture was reduced on a PAF, coercivity of $2.0 \mathrm{kOe}$ was reached after the same treatment. Considering the XRD patterns, it is concluded that the ordering process starts at $400^{\circ} \mathrm{C}$. It was reported that, with $\mathrm{Ag}$ addition, the

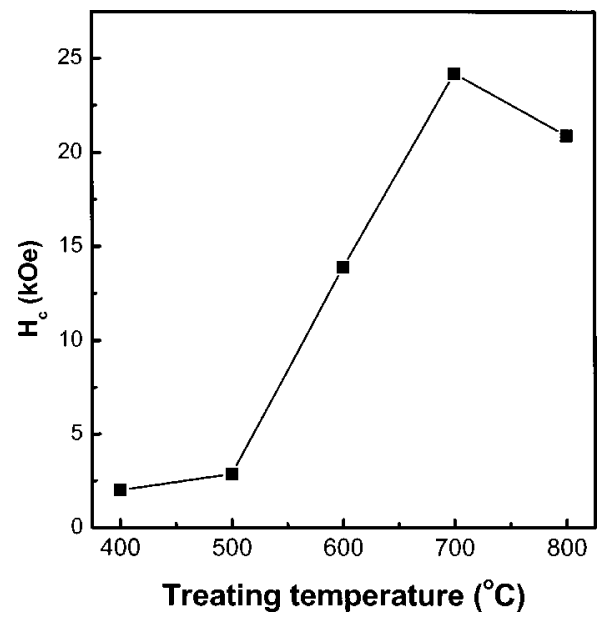

FIG. 3. Coercivities of CoPt hard magnetic films vs treating temperatures. All the samples were treated for $2 \mathrm{~h}$ in flowing hydrogen.

formation temperature of the $\mathrm{CoPt} L 1_{0}$ phase in $\mathrm{CoPt} / \mathrm{SiO}_{2}$ multilayers starts at $550{ }^{\circ} \mathrm{C} .^{7}$ By adding $\mathrm{Sn}, \mathrm{Pb}, \mathrm{Sb}$, and $\mathrm{Bi}$, the ordering temperature of $L 1_{0} \mathrm{CoPt}$ decreased to $400{ }^{\circ} \mathrm{C} .{ }^{8}$ For $\mathrm{Co} / \mathrm{Pt}$ multilayers, it was estimated that the activation energy for the ordering is $2.1 \mathrm{eV}$, which is lower than the self-diffusion energy of $\mathrm{Pt}$ and $\beta$-Co. The possible reasons for this lower energy are gradient diffusion and the large chemical diffusivity of Co in Pt. ${ }^{9}$ In our case, the Co and Pt atoms are released one-by-one during reduction, but the releasing does not occur simultaneously for Pt and Co. Pt is reduced first, followed by Co. The newly released Co atom may have higher chemical activity, which make its diffusion easier to neighboring Pt particles, so the ordering starts from a lower temperature.

Figure 3 shows the coercivities of the films versus treating temperatures. All samples were treated in flowing hydrogen for $2 \mathrm{~h}$. Although CoPt $L 1_{0}$ phase ordering began at $400{ }^{\circ} \mathrm{C}$, the coercivity is lower when the treating temperature

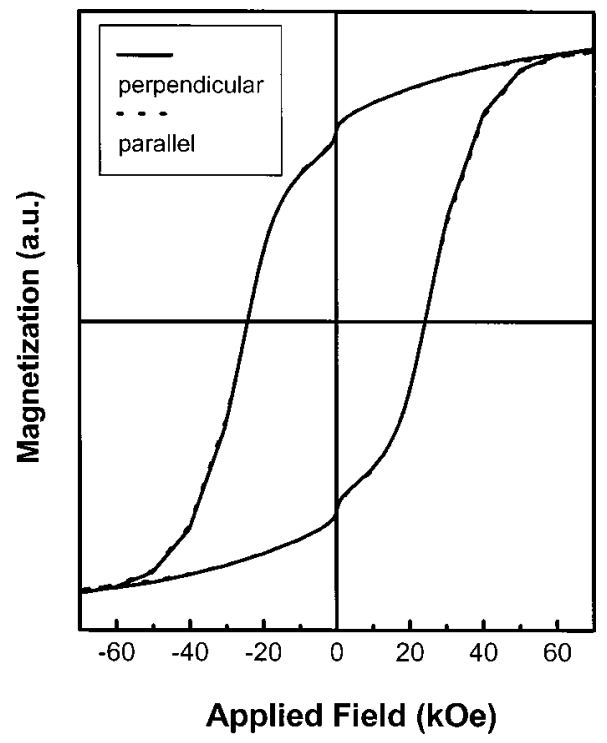

FIG. 4. Two hysteresis loops of a sample treated at $700{ }^{\circ} \mathrm{C}$ for $2 \mathrm{~h}$ and measured with the external field perpendicular and parallel to the film. The coercivity is $24.2 \mathrm{kOe}$. 


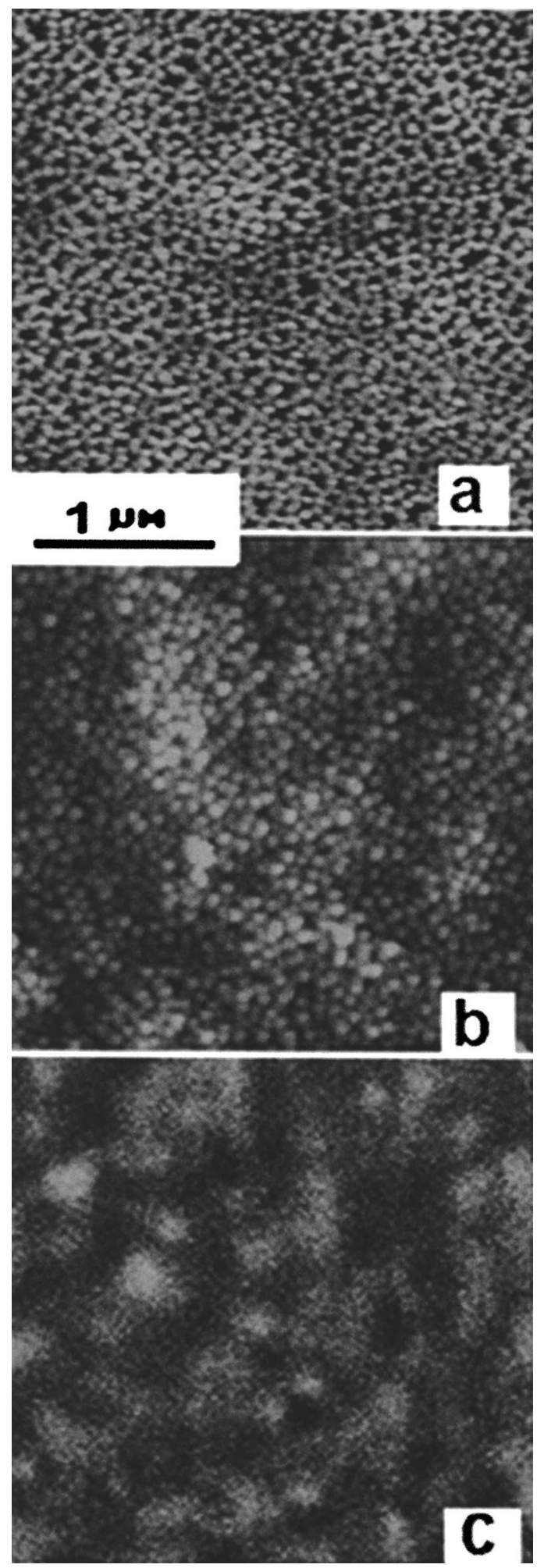

FIG. 5. AFM topographies: (a) as prepared PAF, (b) loaded PAF treated at $700{ }^{\circ} \mathrm{C}$ for $2 \mathrm{~h}$, and (c) MFM image on the same region (b).

is less than $500^{\circ} \mathrm{C}$. Higher coercivity is reached only when the treating temperature is higher than $600^{\circ} \mathrm{C}$. The coercivity of CoPt nanoparticles with $L 1_{0}$ structure originates from its magnetocrystalline anisotropy $K_{u}$, which is associated with the degree of its chemical order. It depends strongly on the treating temperature, because high temperature treatment is necessary to optimize the chemical ordering and to realize a high coercivity. When the treating temperature is $600^{\circ} \mathrm{C}$ or higher, the coercivity increases drastically, reaching a maximum value of $24.2 \mathrm{kOe}$ at $700^{\circ} \mathrm{C}$. Further increase of treating temperature decreases the coercivity. Figure 4 shows two hysteresis loops of a sample reduced at $700{ }^{\circ} \mathrm{C}$ for $2 \mathrm{~h}$, measured with external field perpendicular and parallel to the film. No anisotropic behavior was observed, which holds true for other samples treated at different temperatures.

The average CoPt particle sizes were extracted from the $\mathrm{x}$-ray patterns using the Scherrer formula. As the treating temperature increase, the average size of the CoPt particles increases from $18 \mathrm{~nm}$ (treated at $600^{\circ} \mathrm{C}$ ) to $32 \mathrm{~nm}$ (treated at $800^{\circ} \mathrm{C}$ ). When the film is treated at $600^{\circ} \mathrm{C}$ for $2 \mathrm{~h}$, the remanence ratio is 0.72 , as compared to the remanence ratio of 0.5 for randomly oriented, noninteracting StonerWohlfarth particles. This higher remanence ratio suggests that the CoPt nanoparticles form agglomerates so that exchange coupling between them increases the remanence ratio.

\section{Film topography and MFM images}

Figures 5(a) and 5(b) are topographies of as prepared $\mathrm{PAF}$ and a CoPt hard magnetic film (treated at $700{ }^{\circ} \mathrm{C}$ for 2 h), respectively. Figure 5(c) is a MFM image on the same area as Fig. 5(b). Closely packed pores with diameter around $100 \mathrm{~nm}$ were observed by AFM examination in as prepared PAF. After solution loading and hydrogen reduction, the pore openings are partially covered by the CoPt particles. The MFM images show that the film has maze-like domain structure, which indicates that particles are coupled together to form domains with sizes of order $300 \mathrm{~nm}$.

\section{CONCLUSION}

CoPt hard magnetic films were produced by loading aqueous solution of CoPt mixture salt into PAF and employing hydrogen reduction at elevated temperature. The highest coercivity value is $24.2 \mathrm{kOe}$. The ordering of $L 1_{0} \mathrm{CoPt}$ starts from $400{ }^{\circ} \mathrm{C}$. The partial crystallization of alumina matrix does not affect the chemical ordering and the magnetic properties of the CoPt particles. The AFM images reveal that the pores of PAF substrate are partially covered with CoPt particles. The hard magnetic film has a maze-like domain structure.

\section{ACKNOWLEDGMENTS}

This research work is supported by DOE, AFOSR, CMRA, and NRI.

${ }^{1}$ S. H. Sun, C. B. Murray, D. Weller, L. Folks, and A. Moser, Science 287, 1989 (2000).

${ }^{2}$ C. P. Luo, S. H. Liou, L. Gao, Y. Liu, and D. J. Sellmyer, Appl. Phys. Lett. 77, 2225 (2000).

${ }^{3}$ H. Zeng, S. Sun, T. S. Vedantam, J. P. Liu, Z.-R. Dai, and Z.-L. Wang, Appl. Phys. Lett. 80, 2583 (2002).

${ }^{4}$ J. P. Liu, C. P. Luo, Y. Liu, and D. J. Sellmyer, Appl. Phys. Lett. 72, 483 (1998).

${ }^{5}$ Y. C. Sui and J. M. Saniger, Mater. Lett. 48, 127 (2001).

${ }^{6}$ B. Baker and R. Pearson, J. Electrochem. Soc. 119, 160 (1972).

${ }^{7}$ T. Maeda, T. Kai, A. Kikitsu, T. Nagase, and J. Akiyama, Appl. Phys. Lett. 80, 2147 (2002)

${ }^{8}$ O. Kitakami, Y. Shimada, K. Oikawa, H. Daimon, and K. Fukamichi, Appl. Phys. Lett. 78, 1104 (2001).

${ }^{9}$ D. M. Artymowicz and B. M. Clemens, J. Cryst. Growth 83, 169 (1996). 